\title{
The hepatocyte growth factor antagonist NK4 inhibits indoleamine-2,3-dioxygenase expression via the c-Met-phosphatidylinositol 3-kinase-AKT signaling pathway
}

\author{
DONGDONG WANG $^{1,3}$, YASUSHI SAGA ${ }^{1}$, NAOTO SATO ${ }^{1}$, TOSHIKAZU NAKAMURA ${ }^{4}$, \\ OSAMU TAKIKAWA ${ }^{5}$, HIROAKI MIZUKAMI ${ }^{2}$, SHIGEKI MATSUBARA ${ }^{1}$ and HIROYUKI FUJIWARA ${ }^{1}$ \\ ${ }^{1}$ Department of Obstetrics and Gynecology, and ${ }^{2}$ Division of Genetic Therapeutics, Center for Molecular Medicine, \\ School of Medicine, Jichi Medical University, Tochigi, Japan; ${ }^{3}$ Department of Obstetrics and Gynecology, Shengjing \\ Affiliated Hospital of China Medical University, Shenyang, Liaoning, P.R. China; ${ }^{4}$ Kringle Pharma Joint Research \\ Division for Regenerative Drug Discovery, Center for Advanced Science and Innovation, Osaka University, Osaka; \\ ${ }^{5}$ National Institute for Longevity Sciences, National Center for Geriatrics and Gerontology, Aichi, Japan
}

Received October 16, 2015; Accepted November 18, 2015

DOI: $10.3892 /$ ijo.2016.3486

\begin{abstract}
Indoleamine-2,3-dioxygenase (IDO) is an immunosuppressive enzyme involved in tumor malignancy. However, the regulatory mechanism underlying its involvement remains largely uncharacterized. The present study aimed to investigate the hypothesis that NK4, an antagonist of hepatocyte growth factor (HGF), can regulate IDO and to characterize the signaling mechanism involved. Following successful transfection of the human ovarian cancer cell line SKOV-3 (which constitutively expresses IDO) with an NK4 expression vector, we observed that NK4 expression suppressed IDO expression; furthermore, NK4 expression did not suppress cancer cell growth in vitro [in the absence of natural killer (NK) cells], but did influence tumor growth in vivo. In addition, NK4 enhanced the sensitivity of cancer cells to NK cells in vitro and promoted NK cell accumulation in the tumor stroma in vivo. In an effort to clarify the mechanisms by which NK4 interacts with IDO, we performed investigations utilizing various biochemical inhibitors. The results of these investigations were as follows. First, c-Met (a receptor of HGF) tyrosine kinase inhibitor PHA-665752, and phosphatidylinositol 3-kinase (PI3K) inhibitor LY294002 both suppress IDO expression. Second, enhanced expression of PTEN (a known tumor suppressor) via negative regulation within a PI3K-AKT pathway, inhibits IDO expression. Conversely, neither the MEK1/2 inhibitor U0126 nor the STAT3 inhibitor WP1066 affects IDO expression.
\end{abstract}

Correspondence to: Dr Yasushi Saga, Department of Obstetrics and Gynecology, School of Medicine, Jichi Medical University, 3311-1 Yakushiji, Shimotsuke, Tochigi 329-0498, Japan

E-mail: saga@jichi.ac.jp

Key words: NK4, hepatocyte growth factor, indoleamine-2,3dioxygenase, PTEN, ovarian cancer
These results suggest that NK4 inhibits IDO expression via a c-Met-PI3K-AKT signaling pathway.

\section{Introduction}

Indoleamine-2,3-dioxygenase (IDO) is known to be an immunosuppressive enzyme. IDO was initially characterized in terms of its catalysis of the first and rate-limiting step in the kynurenine pathway of tryptophan catabolism (1-3). It has since been reported that most tumors express IDO (4) and that IDO can contribute to tumor-induced immunosuppression by starving natural killer (NK)/T cells, which are sensitive to tryptophan deficiency (4-7). In this situation, tumor cells can escape immune surveillance via the action of IDO. Malignant tumors are also reportedly stimulated by proinflammatory mediators, such as interferons and other cytokines, to produce IDO $(8,9)$. However, the regulatory mechanisms related to IDO and malignancy remain largely uncharacterized.

Hepatocyte growth factor (HGF) is a heterodimeric molecule that plays a key role in the regulation of migration, invasion and angiogenesis in cancer (10-13). It is composed of an $\alpha$-chain containing the $\mathrm{N}$-terminal hairpin domain and 4 kringle domains, and a serine protease-like $\beta$-chain (14). Therefore, NK4 is a variant form of HGF, comprising the $\mathrm{N}$-terminal and subsequent 4 kringle domains of HGF (15). As NK4 retains binding capacity to the HGF receptor c-Met, NK4 competes with HGF and inhibits the function of $\operatorname{HGF}(15,16)$. Thus, NK4 functions as an antagonist of HGF. Numerous reports have shown that NK4 inhibits growth, invasion, dissemination and angiogenesis in malignant tumors (16-24). Furthermore, NK4 reportedly inhibits the function of angiogenesis factors such as VEGF and bFGF, regardless of HGF-c-Met signaling $(16,17)$.

Recently, it has been reported that NK4 expression by gene transfer (at the tumor site) enhances tumor-specific cytotoxic $\mathrm{T}$ lymphocyte (CTL) activation, resulting in complete murine colon cancer cell line (CT26) tumor regression in vivo (22). While IDO is not specifically mentioned in the present 
study (22), it has been reported in other studies that CT26 can produce IDO (25). These results suggest the possibility that NK4 may exert potent antitumor activity, at least partially, by enhancing the host's tumor immunity via the regulation of IDO expression.

We conducted the experiments described below in an effort to investigate the hypothesis that NK4 regulates IDO and to characterize the signaling mechanism involved.

\section{Materials and methods}

Cell lines and culture. The human ovarian cancer cell line SKOV-3 (26) (American Type Culture Collection, Manassas, VA, USA) was cultured in RPMI-1640 medium (Gibco, Grand Island, NY, USA) containing 10\% inactivated fetal calf serum (Sigma, St. Louis, MO, USA), $100 \mathrm{U} / \mathrm{ml}$ penicillin, and $100 \mu \mathrm{g} / \mathrm{ml}$ streptomycin (Gibco) at $37^{\circ} \mathrm{C}$ in a $5 \% \mathrm{CO}_{2}$ atmosphere for no longer than 8 weeks after recovery from frozen stocks.

The NK cell line KHYG-1 (27) was purchased from the Japanese Collection of Research Bioresources (JCRB; Osaka, Japan). Cells were cultured in RPMI1-640 medium supplemented with $100 \mathrm{nM}$ of human interleukin-2 (R\&D Systems, Inc., Minneapolis, MN, USA) and 10\% inactivated fetal calf serum (Sigma) at $37^{\circ} \mathrm{C}$ in a $5 \% \mathrm{CO}_{2}$ atmosphere for no longer than 8 weeks after recovery from frozen stocks.

Antibodies and inhibitors. Anti-human-IDO monoclonal antibody was prepared and utilized as previously reported (8). Anti-human-actin (Sigma), anti-mouse-CD49b(R\&DSystems), anti-HGF- $\alpha$ (Santa Cruz Biotechnology, Inc., Santa Cruz, CA, USA), anti-phospho-c-Met, anti-c-Met, anti-phospho-AKT, anti-AKT, anti-phospho-ERK, anti-ERK, anti-phosphoSTAT3 and anti-STAT3 (Cell Signaling Technology, Inc., Danvers, MA, USA) antibodies were purchased and utilized according to the manufacturer's instructions.

The c-Met tyrosine kinase inhibitor PHA-665752((3Z)-5[(2,6-dichlorobenzyl)sulfonyl]-3-[(3,5-dimethyl-4-\{[(2R) -2-(pyrrolidin-1-ylmethyl)pyrrolidin-1-yl]carbonyl\}-1Hpyrrol-2-yl)methylene]-1,3-dihydro-2H-indol-2-one; Merck KGaA, Darmstadt, Germany) (28), the phosphatidylinositol 3-kinase (PI3K) inhibitor LY294002 (2-(4-morpholinyl)-8phenyl-4H-1-benzopyran-4-one; Cell Signaling Technology) (29), the MEK1/2 inhibitor U0126 (1,4-diamino-2,3-dicyano1,4-bis[2-aminophenylthio] butadiene; Cell Signaling Technology) (30), and the STAT3 inhibitor WP1066 ((2E)-3(6-Bromo-2-pyridinyl)-2-cyano-N-[(1S)-1-phenylethy]-2propenamide P; Santa Cruz Biotechnology) (31) were purchased and were utilized according to the corresponding manufacturer's instructions.

Experimental and control cell lines. The NK4, PTEN and luciferase (LUC) expression plasmid vectors that were used in the present study have been previously described $(18,32-35)$. These vectors were transfected into SKOV-3 using Lipofectamine-LTX and Plus reagent (Invitrogen, Carlsbad, CA, USA) according to the manufacturer's instructions. The cells were selected using $10 \mu \mathrm{g} / \mathrm{ml}$ blasticidin S hydrochloride (Funakoshi Co., Ltd., Tokyo, Japan). Resistant clones were obtained after 4 weeks as SKOV-3/NK4, SKOV-3/PTEN and
SKOV-3/LUC (control). The cells were subsequently maintained in the presence of $10 \mu \mathrm{g} / \mathrm{ml}$ blasticidin S hydrochloride.

Exposure to inhibitors. Before protein extraction for western

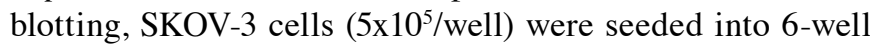
plates and cultured in RPMI-1640 medium containing $10 \%$ fetal calf serum with varying concentrations of inhibitors $(0,1$ or $10 \mu \mathrm{M})$ overnight.

Western blotting. Ten micrograms of protein extracted from a homogenate of cultured cells or $10 \mu \mathrm{l}$ of culture supernatants were mixed with $2 X$ SDS-PAGE sample buffer $[120 \mathrm{mM}$ Tris- $\mathrm{HCl}(\mathrm{pH} 6.8), 4 \%$ SDS, $20 \%$ glycerol, $0.004 \%$ bromophenol blue and $10 \% 2$-mercaptoethanol]. The resulting preparations were incubated at $95^{\circ} \mathrm{C}$ for $2 \mathrm{~min}$ and electrophoresed on a $0.1 \%$ SDS -5 or $10 \%$ polyacrylamide gel, prior to blotting onto a polyfluorovinylidene membrane. These membranes were then blocked with Non-Protein Blocking Agent (ATTO Corp., Tokyo, Japan) at room temperature for $1 \mathrm{~h}$ and incubated with antibodies described above for $1 \mathrm{~h}$ at room temperature. The membranes were washed with phosphate-buffered saline (PBS)-Tween-20 three times, and incubated with several horseradish peroxidase-conjugated secondary antibodies. Signals were detected by chemiluminescence (ECL Kit; Amersham Biosciences, Piscataway, NJ, USA) via X-ray film.

In vitro cell growth kinetics. SKOV-3/NK4 and SKOV-3/LUC cells (500 of each line) were seeded into the wells of 96-well plates and cultured in RPMI-1640 medium containing 10\% fetal calf serum. Every $24 \mathrm{~h}$, cells were counted using a colorimetric assay in conjunction with the Cell Proliferation kit II (XTT) (Boehringer Mannheim GmbH Biochemica, Mannheim, Germany) and a growth curve was derived from these results.

Sensitivity of transfectants to NK cells in vitro. The sensitivity of SKOV-3/NK4 and SKOV-3/LUC cells to NK cells was investigated by colorimetric assay using XTT. SKOV-3/NK4 and SKOV-3/LUC cells (500 of each line) were seeded into a 96-well plate and co-cultured with KHYG-1 cells $(0,500$, $1,000,2,000$ or 4,000 cells) in RPMI-1640 medium containing $10 \%$ fetal calf serum for $72 \mathrm{~h}$. After three washes with PBS to exclude KHYG-1 cells completely, the viable cell count was determined by colorimetric assay and calculated as the percent of control cells (cultured without KHYG-1 cells).

Experimental animals. Four- to six-week-old female BALB/c nude mice (Japan Clea Laboratories, Tokyo, Japan) were used. All animal experiments were conducted according to the institutional and national guidelines for animal experiments.

Subcutaneous tumor growth in vivo. SKOV-3/NK4 and SKOV-3/LUC cells $\left(5 \times 10^{6}\right.$ cells of each line) were inoculated subcutaneously into the backs of mice to induce tumor growth. The tumor volume [(long diameter) $\mathrm{x}$ (short diameter) ${ }^{2} \mathrm{x} 1 / 2$ ] was measured twice a week and used to obtain the tumor growth curves.

Immunohistochemical staining. At 1 week after subcutaneous tumor cell inoculation, mice were sacrificed under isoflurane 
anesthesia and the tumor was removed. After formalin fixation, paraffin sections were prepared, deparaffinized, and treated with hydrogen peroxide for 30 min to block endogenous peroxidase. The sections were then reacted with a 1:10 dilution $(5 \mu \mathrm{g} / \mathrm{ml})$ of anti-mouse CD $49 \mathrm{~b}$ primary antibody for $16 \mathrm{~h}$ at room temperature, washed three times with PBS, and then incubated with enzyme-conjugated streptavidin for $30 \mathrm{~min}$. The sections were again washed with PBS 3 times, and color was developed using the diaminobenzidine method. The number of stained NK cells was counted under high-power magnification (x200).

Statistical analysis. Significance testing between the 2 groups was performed using Student's t-test. A P-value of $<0.05$ was considered significant.

\section{Results}

Establishing an NK4-expressing cell line and determining its IDO expression. NK4 expression was detected by western blotting at the position corresponding to a molecular weight of $67 \mathrm{kDa}$ in SKOV-3/NK4 culture supernatant samples. No NK4 expression was detected in the culture supernatant of parent SKOV-3 or SKOV-3/LUC. In contrast, parental SKOV-3 and SKOV-3/LUC showed evident IDO expression, while SKOV-3/NK4 did not show IDO expression (Fig. 1A). These results suggest that the expression of NK4 inhibits IDO expression.

In vitro cell growth kinetics. Growth curve analyses of SKOV-3/NK4 and SKOV-3/LUC cells showed no significant differences between the two groups, suggesting that the expression of NK4 did not affect cell growth in vitro (data not shown).

Sensitivity of transfectants to NK cells in vitro. The proportion of viable tumor cells co-cultured with NK cells is shown in Fig. 1B. The percent survival of SKOV-3/NK4 cells was significantly lower than that of the control cells, indicating that the expression of NK4 enhanced the sensitivity of tumor cells against NK cells.

Tumor growth in vivo. Both SKOV-3/NK4 and control cells formed small nodules 1 week after inoculation (Fig. 1C). Subsequently, the tumors in the control group became enlarged, whereas those in the SKOV-3/NK4 group were barely increased in size, suggesting that the expression of $\mathrm{NK} 4$ inhibited tumor growth in vivo.

Number of NK cells in the tumor stroma. Immunostaining of $\mathrm{NK}$ cells revealed accumulation of NK cells in the stroma of SKOV-3/NK4 and control subcutaneous tumors (Fig. 2A). The number of NK cells $(38 \pm 10)$ that accumulated in the SKOV-3/ NK4 tumors was significantly higher than that $(5 \pm 2)$ in the control tumors $(\mathrm{P}<0.01)$ (Fig. 2B). These results suggest that the expression of NK4 promoted NK cell accumulation around the tumor.

Establishing a PTEN-overexpressing cell line and determining its IDO expression. Strong PTEN expression was detected by western blotting at the position corresponding to a molecular
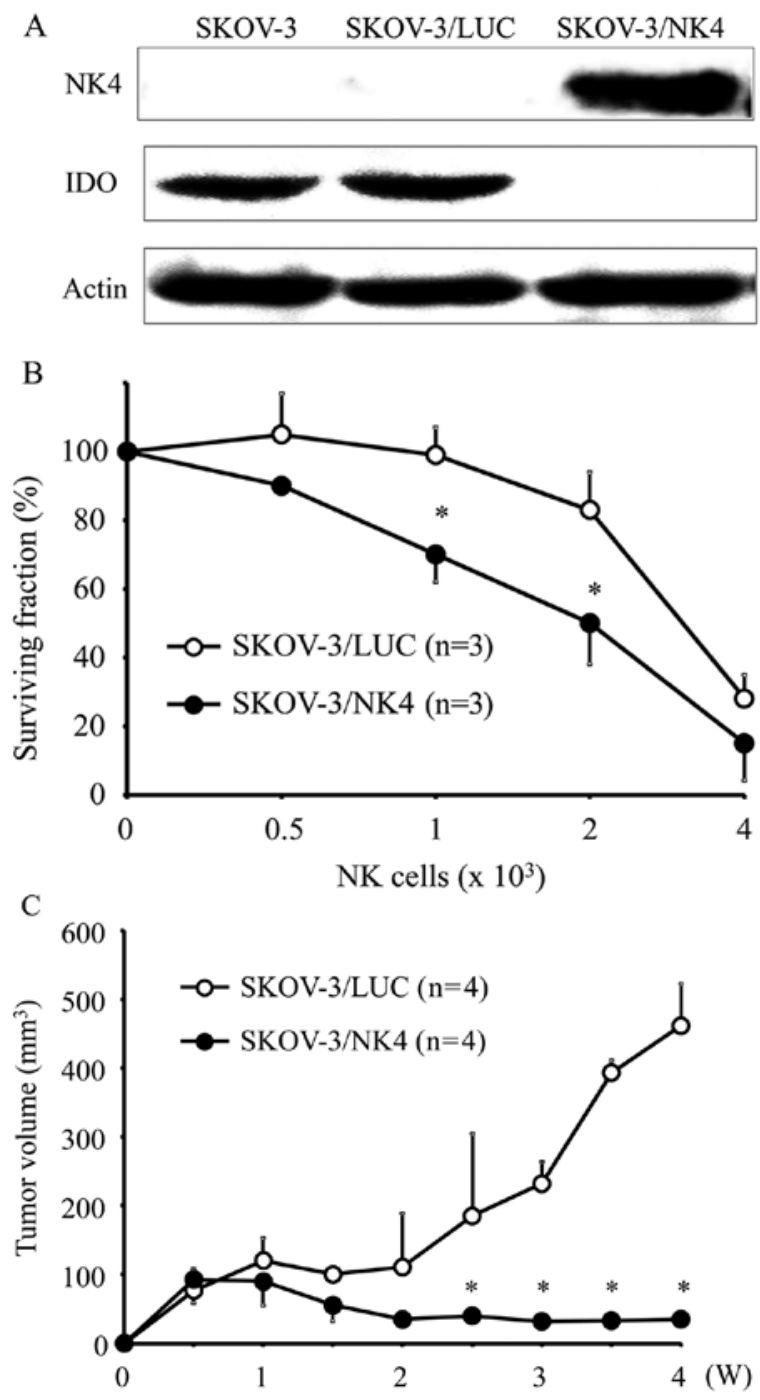

Figure 1. Western blot detection of NK4 and IDO. NK4 expression was detected in the culture supernatant of SKOV-3/NK4 cells, while no NK4 expression was detected in the culture supernatant of parent SKOV-3 or SKOV-3/LUC cells. In contrast, parental SKOV-3 or SKOV-3/LUC showed evident IDO expression, while SKOV-3/NK4 did not show IDO expression (A). The percentage of viable tumor cells remaining after co-culture with NK cells. The percent survival of SKOV-3/NK4 cells was significantly lower than that of control cells; ${ }^{*} \mathrm{P}<0.05$. Results are expressed as mean $\pm \mathrm{SD}(\mathrm{B})$. Subcutaneous tumor growth curves of SKOV-3/NK4 and control cells. Both groups of cells formed small nodules 1 week after inoculation. Subsequently, the tumors in the control group enlarged substantially, whereas those in the SKOV-3/NK4 group increased only minimally; ${ }^{*} \mathrm{P}<0.05$. Results are expressed as mean $\pm \mathrm{SD}(\mathrm{C})$.

weight of $55 \mathrm{kDa}$ in SKOV-3/PTEN, while only weak PTEN expression was detected in parent SKOV-3 and SKOV-3/LUC cells. In contrast, parental SKOV-3 or SKOV-3/LUC showed evident IDO expression, while SKOV-3/PTEN did not show IDO expression. These results suggest that overexpression of PTEN inhibits IDO expression (Fig. 3).

Inhibitors and IDO expression. As shown in Fig. 4A, the c-Met tyrosine kinase inhibitor PHA-665752 inhibited c-Met phosphorylation of SKOV-3 in a concentration-dependent manner. Similarly, it suppressed IDO expression of SKOV-3 in a concentration-dependent manner. The PI3K inhibitor LY294002 inhibited AKT phosphorylation of SKOV-3 at the 
A

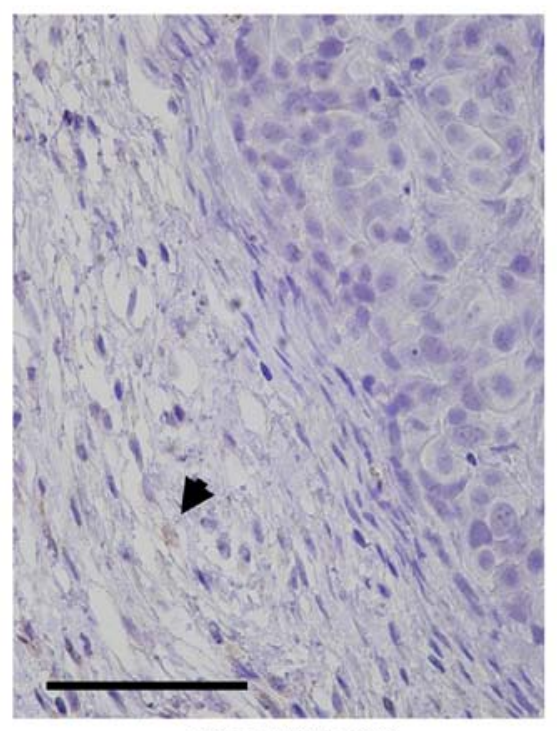

SKOV-3/LUC

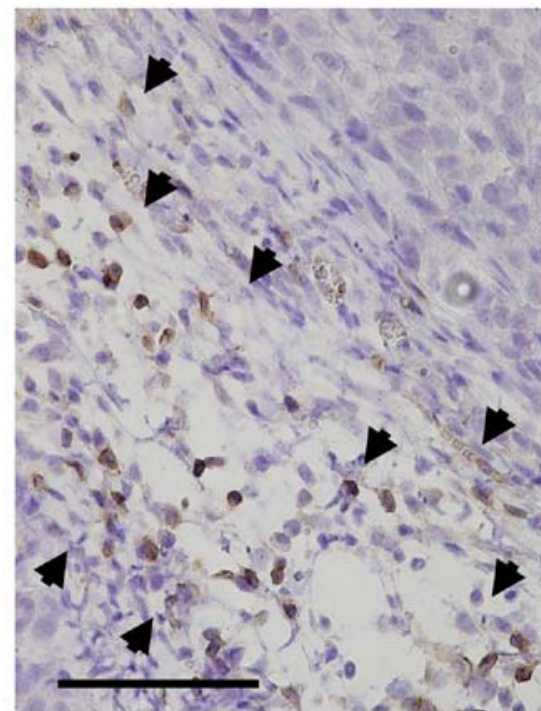

SKOV-3/NK4

B

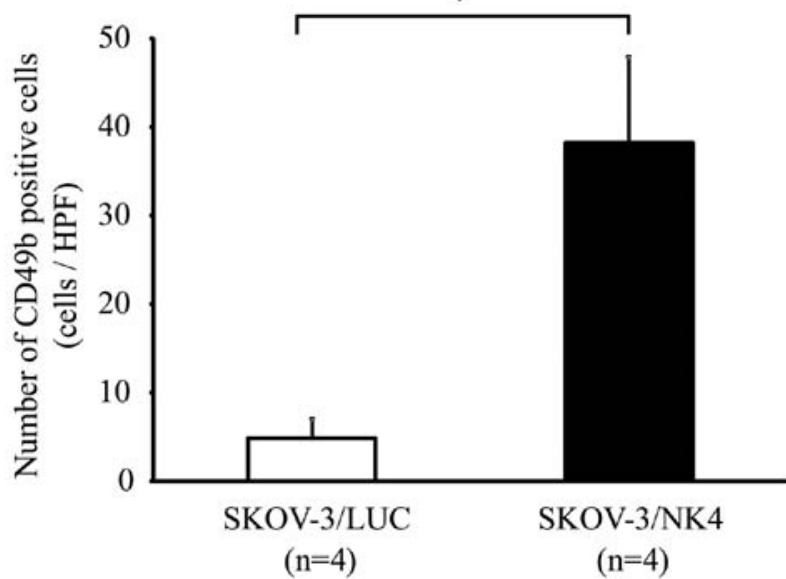

Figure 2. CD49b expression in SKOV-3/NK4 and control subcutaneous tumors. The black arrowhead indicates NK cells accumulated in the tumor stroma. Bars indicate $100 \mu \mathrm{m}$ (A). The number of NK cells per high-power (magnification, $\mathrm{x} 200$ ) microscopy field. The number of NK cells (38 \pm 10 ) that accumulated in the SKOV-3/NK4 tumors was significantly higher than that $(5 \pm 2)$ in the control tumors; ${ }^{*} \mathrm{P}<0.01$. Results are expressed as mean \pm SD (B).

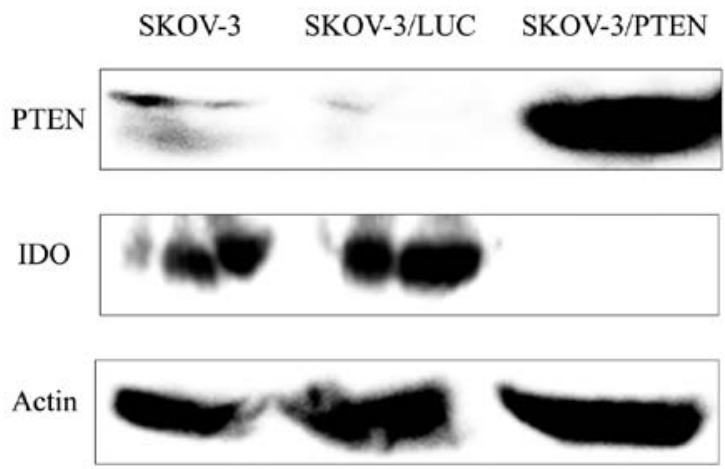

Figure 3. Detection of PTEN and IDO by western blotting. Strong PTEN expression was detected in SKOV-3/PTEN cells, while weak PTEN expression was detected in parent SKOV-3 and SKOV-3/LUC cells. In contrast, parental SKOV-3 or SKOV-3/LUC cells showed evident IDO expression, while SKOV-3/PTEN cells did not show IDO expression.

concentration of $10 \mu \mathrm{M}$. Similarly, it suppressed IDO expression of SKOV-3 (Fig. 4B) at the concentration of $10 \mu \mathrm{M}$. On the other hand, although the MEK1/2 inhibitor U0126 inhibited ERK (which is a downstream signaling factor of MEK) phosphorylation of SKOV-3 in a concentration-dependent manner and the STAT3 inhibitor WP1066 inhibited STAT3 phosphorylation of SKOV-3 at the concentration of $10 \mu \mathrm{M}$, they did not affect IDO expression of SKOV-3 (Fig. 4C and D).

\section{Discussion}

The experiments described above aimed to investigate the hypothesis that NK4 influences IDO expression, and to clarify the signaling pathway involved. First, we transfected an NK4 expression vector into a human ovarian cancer cell line constitutively expressing IDO in order to examine the relationship between NK4 expression and IDO expression. We found that the NK4-expressing cell line did not express IDO. This indicates that NK4 suppressed the expression of IDO by these cells. Furthermore, experimentation using this NK4-expressing cell line yielded results similar to those of a previous study, which used an IDO-downregulated cell line 
A

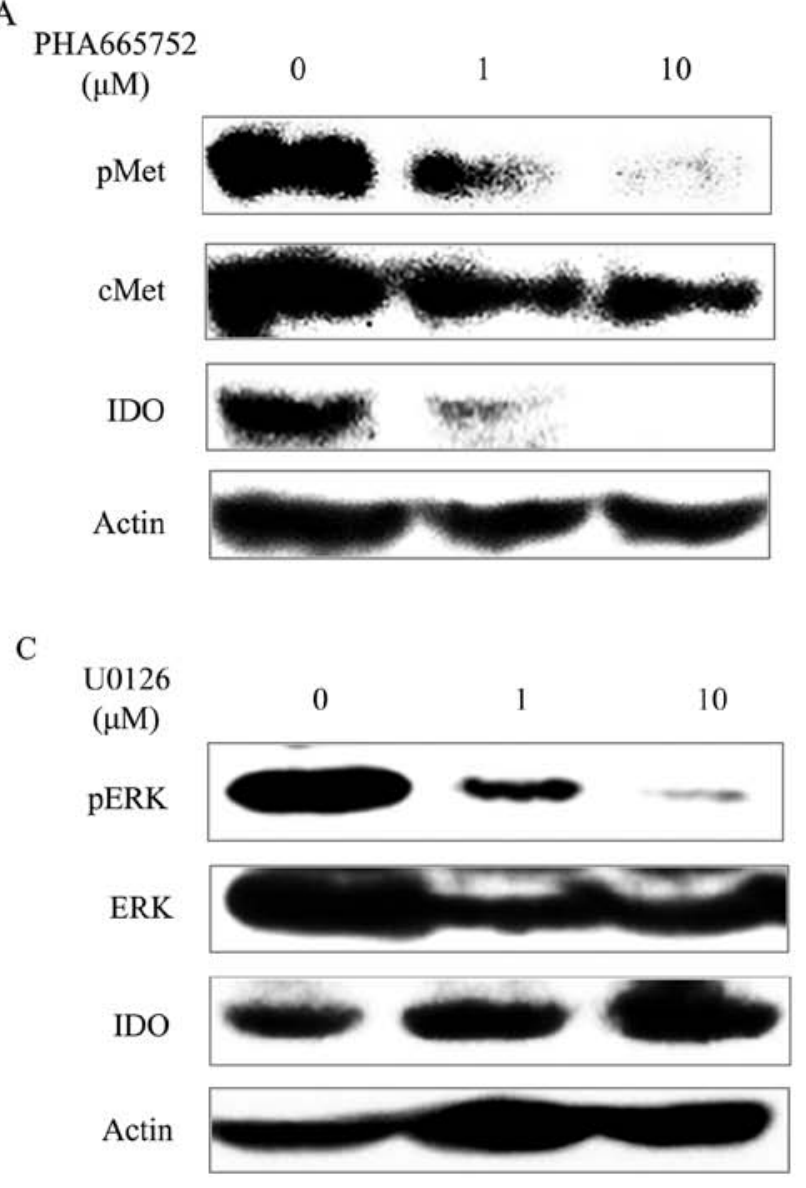

B

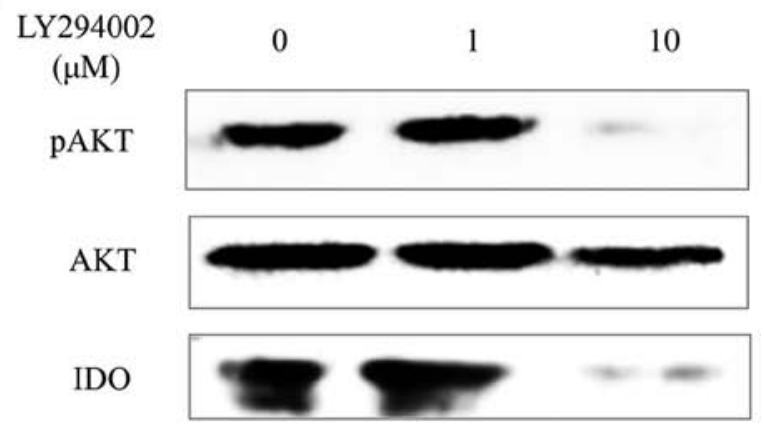

Actin

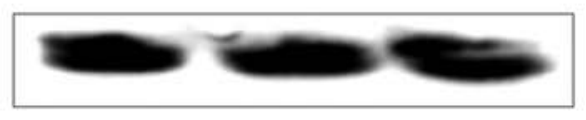

D

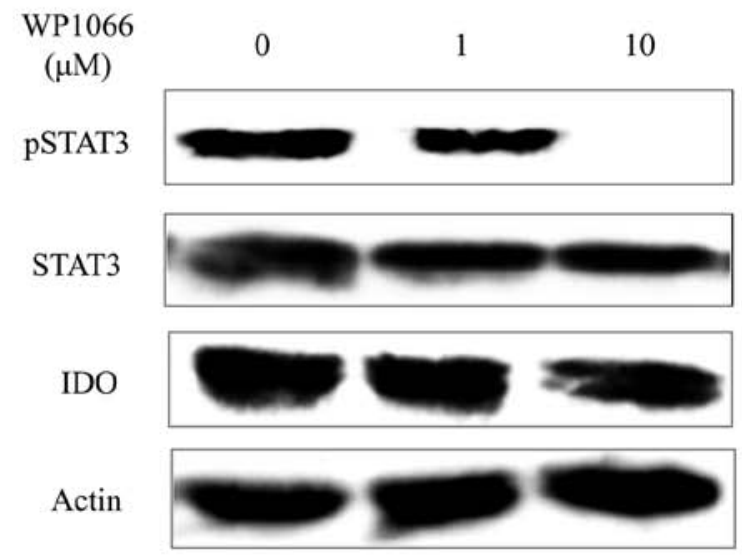

Figure 4. Effects of PHA-665752 on c-Met phosphorylation and IDO expression in SKOV-3 cells. PHA-665752 inhibited both c-Met phosphorylation and IDO expression of SKOV-3 cells in a concentration-dependent manner (A). Effects of LY294002 on AKT phosphorylation and IDO expression in SKOV-3 cells. LY294002 inhibited both AKT phosphorylation and IDO expression of SKOV-3 cells at the concentration of $10 \mu \mathrm{M}$ (B). Effects of U0126 on ERK phosphorylation and IDO expression in SKOV-3 cells. While U0126 inhibited ERK phosphorylation of SKOV-3 cells in a concentration-dependent manner, it did not affect their IDO expression (C). Effects of WP1066 on STAT3 phosphorylation and IDO expression in SKOV-3 cells. WP1066 inhibited STAT3 phosphorylation of SKOV-3 cells at the concentration of $10 \mu \mathrm{M}$, but did not affect their IDO expression (D).

transfected with a short hairpin RNA vector targeting IDO (36). Therefore, NK4 expression did not influence cancer cell growth in vitro, but controlled tumor growth in vivo. In addition, it enhanced the sensitivity of cancer cells to NK cells in vitro and promoted NK cell accumulation in the tumor stroma in vivo. These findings indicate that NK4 can inhibit cancer growth in vivo by promoting NK cell accumulation via the inhibition of IDO expression in tumors, suggesting that NK4 represents a potentially useful immunotherapeutic anticancer agent.

In order to clarify the mechanism by which NK4 controls IDO, we performed an investigation utilizing various biochemical inhibitors. It has been reported that while NK4 is known to function in the c-Met signaling pathway as an antagonist of HGF, it may also have other unknown functions unrelated to the c-Met signaling pathway $(16,17)$. In order to investigate the known function, we utilized the c-Met tyrosine kinase inhibitor PHA-665752. While PHA-665752 inhibited c-Met phosphorylation, it also suppressed IDO expression. These results suggest that NK4 suppresses IDO expression via the c-Met signaling pathway. The PI3K-AKT, MAPK/ ERK, and the JAK-STAT pathways are known as signal path- ways downstream of c-Met. In the present study, while the PI3K inhibitor LY294002 inhibited AKT phosphorylation of cancer cells, it also suppressed IDO expression. In addition, enhanced expression of PTEN, which suppresses tumor by negatively regulating the PI3K-AKT pathways $(37,38)$, inhibited IDO expression of cancer cells. Conversely, while the MEK1/2 inhibitor U0126 and the STAT3 inhibitor WP1066 both inhibited ERK and STAT3 phosphorylation, neither affected IDO expression. These results suggest that NK4 inhibits IDO expression via the c-Met-PI3K-AKT signaling pathway.

Recently, it has been reported that imatinib mesylate, a small-molecule inhibitor of KIT and BCR-ABL tyrosine kinase, inhibits IDO expression of gastrointestinal stromal tumors via the PI3K-AKT pathway (39). Results from both that study and the present suggest the possibility that various tyrosine kinase receptors control IDO expression in malignancies through the PI3K-AKT signaling pathway. Furthermore, the collective results suggest that various molecularly-targeted therapeutic agents that suppress tyrosine kinase may function to enhance the cancer immunity of the host via the inhibition of IDO. 


\section{Acknowledgements}

The present study was supported by a JSPC KAKENHI (grant no. 25462606) from Grant-in-Aid for Scientific Research from the Ministry of Education, Culture, Sports, Science and Technology of Japan (Y.S.).

\section{References}

1. Higuchi K and Hayaishi O: Enzymic formation of D-kynurenine from D-tryptophan. Arch Biochem Biophys 120: 397-403, 1967.

2. Yamamoto $S$ and Hayaishi O: Tryptophan pyrrolase of rabbit intestine. D- and L-tryptophan-cleaving enzyme or enzymes. J Biol Chem 242: 5260-5266, 1967.

3. Shimizu T, Nomiyama S, Hirata F and Hayaishi O: Indoleamine 2,3-dioxygenase. Purification and some properties. J Biol Chem 253: 4700-4706, 1978.

4. Uyttenhove C, Pilotte L, Théate I, Stroobant V, Colau D, Parmentier N, Boon T and Van den Eynde BJ: Evidence for a tumoral immune resistance mechanism based on tryptophan degradation by indoleamine 2,3-dioxygenase. Nat Med 9: 1269-1274, 2003.

5. Munn DH, Zhou M, Attwood JT, Bondarev I, Conway SJ, Marshall B, Brown C and Mellor AL: Prevention of allogeneic fetal rejection by tryptophan catabolism. Science 281: 1191-1193, 1998.

6. Della Chiesa M, Carlomagno S, Frumento G, Balsamo M, Cantoni C, Conte R, Moretta L, Moretta A and Vitale M: The tryptophan catabolite L-kynurenine inhibits the surface expression of NKp46- and NKG2D-activating receptors and regulates NK-cell function. Blood 108: 4118-4125, 2006.

7. Nonaka H, Saga Y, Fujiwara H, Akimoto H, Yamada A, Kagawa S, Takei Y, Machida S, Takikawa O and Suzuki M: Indoleamine 2,3-dioxygenase promotes peritoneal dissemination of ovarian cancer through inhibition of natural killer cell function and angiogenesis promotion. Int J Oncol 38: 113-120, 2011.

8. Takikawa O, Kuroiwa T, Yamazaki F and Kido R: Mechanism of interferon-gamma action. Characterization of indoleamine 2,3-dioxygenase in cultured human cells induced by interferongamma and evaluation of the enzyme-mediated tryptophan degradation in its anticellular activity. J Biol Chem 263: 2041-2048, 1988.

9. Fujigaki S, Saito K, Sekikawa K, Tone S, Takikawa O, Fujii H, Wada H, Noma A and Seishima M: Lipopolysaccharide induction of indoleamine 2,3-dioxygenase is mediated dominantly by an IFN-gamma-independent mechanism. Eur J Immunol 31: 2313-2318, 2001

10. Matsumoto K, Date K, Shimura $\mathrm{H}$ and Nakamura T: Acquisition of invasive phenotype in gallbladder cancer cells via mutual interaction of stromal fibroblasts and cancer cells as mediated by hepatocyte growth factor. Jpn J Cancer Res 87: 702-710, 1996

11. Nakamura T, Matsumoto K, Kiritoshi A, Tano $Y$ and Nakamura T: Induction of hepatocyte growth factor in fibroblasts by tumor-derived factors affects invasive growth of tumor cells: In vitro analysis of tumor-stromal interactions. Cancer Res 57: 3305-3313, 1997.

12. Bussolino F, Di Renzo MF, Ziche M, Bocchietto E, Olivero M, Naldini L, Gaudino G, Tamagnone L, Coffer A and Comoglio PM: Hepatocyte growth factor is a potent angiogenic factor which stimulates endothelial cell motility and growth. J Cell Biol 119 629-641, 1992.

13. Grant DS, Kleinman HK, Goldberg ID, Bhargava MM, Nickoloff BJ, Kinsella JL, Polverini P and Rosen EM: Scatter factor induces blood vessel formation in vivo. Proc Natl Acad Sci USA 90: 1937-1941, 1993.

14. Nakamura T, Nishizawa T, Hagiya M, Seki T, Shimonishi M, Sugimura A, Tashiro K and Shimizu S: Molecular cloning and expression of human hepatocyte growth factor. Nature 342: 440-443, 1989

15. Date K, Matsumoto K, Shimura H, Tanaka M and Nakamura T: $\mathrm{HGF} / \mathrm{NK} 4$ is a specific antagonist for pleiotrophic actions of hepatocyte growth factor. FEBS Lett 420: 1-6, 1997.

16. Matsumoto $\mathrm{K}$ and Nakamura T: Mechanisms and significance of bifunctional NK4 in cancer treatment. Biochem Biophys Res Commun 333: 316-327, 2005.
17. Kuba K, Matsumoto K, Date K, Shimura H, Tanaka M and Nakamura T: HGF/NK4, a four-kringle antagonist of hepatocyte growth factor, is an angiogenesis inhibitor that suppresses tumor growth and metastasis in mice. Cancer Res 60: 6737-6743, 2000.

18. Saga Y, Mizukami H, Suzuki M, Urabe M, Kume A, Nakamura T, Sato I and Ozawa K: Expression of HGF/NK4 in ovarian cancer cells suppresses intraperitoneal dissemination and extends host survival. Gene Ther 8: 1450-1455, 2001.

19. Tomioka D, Maehara N, Kuba K, Mizumoto K, Tanaka M, Matsumoto $\mathrm{K}$ and Nakamura T: Inhibition of growth, invasion, and metastasis of human pancreatic carcinoma cells by NK4 in an orthotopic mouse model. Cancer Res 61: 7518-7524, 2001.

20. Son G, Hirano T, Seki E, Iimuro Y, Nukiwa T, Matsumoto K, Nakamura T and Fujimoto J: Blockage of HGF/c-Met system by gene therapy (adenovirus-mediated NK4 gene) suppresses hepatocellular carcinoma in mice. J Hepatol 45: 688-695, 2006.

21. Du W, Hattori Y, Yamada T, Matsumoto K, Nakamura T, Sagawa M, Otsuki T, Niikura T, Nukiwa T and Ikeda Y: NK4, an antagonist of hepatocyte growth factor (HGF), inhibits growth of multiple myeloma cells: Molecular targeting of angiogenic growth factor. Blood 109: 3042-3049, 2007.

22. Kubota T, Taiyoh H, Matsumura A, Murayama Y, Ichikawa D, Okamoto K, Fujiwara H, Ikoma H, Nakanishi M, Kikuchi S, et al: Gene transfer of NK4, an angiogenesis inhibitor, induces CT26 tumor regression via tumor-specific T lymphocyte activation. Int J Cancer 125: 2879-2886, 2009.

23. Suzuki Y, Sakai K, Ueki J, Xu Q, Nakamura T, Shimada H, Nakamura T and Matsumoto K: Inhibition of Met/HGF receptor and angiogenesis by NK4 leads to suppression of tumor growth and migration in malignant pleural mesothelioma. Int $\mathrm{J}$ Cancer 127: 1948-1957, 2010.

24. Matsumoto G, Omi Y, Lee U, Kubota E and Tabata Y: NK4 gene therapy combined with cisplatin inhibits tumour growth and metastasis of squamous cell carcinoma. Anticancer Res 31: 105-111, 2011.

25. Koblish HK, Hansbury MJ, Bowman KJ, Yang G, Neilan CL, Haley PJ, Burn TC, Waeltz P, Sparks RB, Yue EW, et al: Hydroxyamidine inhibitors of indoleamine-2,3-dioxygenase potently suppress systemic tryptophan catabolism and the growth of IDO-expressing tumors. Mol Cancer Ther 9: 489-498, 2010.

26. Fogh J, Wright WC and Loveless JD: Absence of HeLa cell contamination in 169 cell lines derived from human tumors. J Natl Cancer Inst 58: 209-214, 1977.

27. Yagita M, Huang CL, Umehara H, Matsuo Y, Tabata R, Miyake M, Konaka Y and Takatsuki K: A novel natural killer cell line (KHYG-1) from a patient with aggressive natural killer cell leukemia carrying a p53 point mutation. Leukemia 14: 922-930, 2000.

28. Christensen JG, Schreck R, Burrows J, Kuruganti P, Chan E, Le P, Chen J, Wang X, Ruslim L, Blake R, et al: A selective small molecule inhibitor of c-Met kinase inhibits c-Met-dependent phenotypes in vitro and exhibits cytoreductive antitumor activity in vivo. Cancer Res 63: 7345-7355, 2003.

29. Guo M, Joiakim A and Reiners JJ Jr: Suppression of 2,3,7,8-tetrachlorodibenzo-p-dioxin (TCDD)-mediated aryl hydrocarbon receptor transformation and CYP1A1 induction by the phosphatidylinositol 3-kinase inhibitor 2-(4-morpholinyl)8-phenyl-4H-1- benzopyran-4-one (LY294002). Biochem Pharmacol 60: 635-642, 2000.

30. Favata MF, Horiuchi KY, Manos EJ, Daulerio AJ, Stradley DA, Feeser WS, Van Dyk DE, Pitts WJ, Earl RA, Hobbs F, et al: Identification of a novel inhibitor of mitogen-activated protein kinase kinase. J Biol Chem 273: 18623-18632, 1998.

31. Iwamaru A, Szymanski S, Iwado E, Aoki H, Yokoyama T, Fokt I, Hess K, Conrad C, Madden T, Sawaya R, et al: A novel inhibitor of the STAT3 pathway induces apoptosis in malignant glioma cells both in vitro and in vivo. Oncogene 26: 2435-2444, 2007.

32. Saga Y, Mizukami H, Suzuki M, Kohno T, Urabe M, Ozawa K and Sato I: Overexpression of PTEN increases sensitivity to $\mathrm{SN}-38$, an active metabolite of the topoisomerase I inhibitor irinotecan, in ovarian cancer cells. Clin Cancer Res 8: 12481252, 2002.

33. Saga Y, Mizukami H, Takei Y, Ozawa K and Suzuki M: Suppression of cell migration in ovarian cancer cells mediated by PTEN overexpression. Int J Oncol 23: 1109-1113, 2003. 
34. Takei Y, Saga Y, Mizukami H, Takayama T, Ohwada M, Ozawa K and Suzuki M: Overexpression of PTEN in ovarian cancer cells suppresses i.p. dissemination and extends survival in mice. Mol Cancer Ther 7: 704-711, 2008.

35. Urabe M, Hasumi Y, Ogasawara Y, Matsushita T, Kamoshita N, Nomoto A, Colosi P, Kurtzman GJ, Tobita K and Ozawa K: A novel dicistronic AAV vector using a short IRES segment derived from hepatitis C virus genome. Gene 200: 157-162, 1997.

36. Wang D, Saga Y, Mizukami H, Sato N, Nonaka H, Fujiwara H, Takei Y, Machida S, Takikawa O, Ozawa K, et al: Indoleamine2,3-dioxygenase, an immunosuppressive enzyme that inhibits natural killer cell function, as a useful target for ovarian cancer therapy. Int J Oncol 40: 929-934, 2012.
37. Li J, Yen C, Liaw D, Podsypanina K, Bose S, Wang SI, Puc J, Miliaresis C, Rodgers L, McCombie R, et al: PTEN, a putative protein tyrosine phosphatase gene mutated in human brain, breast, and prostate cancer. Science 275: 1943-1947, 1997.

38. Cantley LC and Neel BG: New insights into tumor suppression: PTEN suppresses tumor formation by restraining the phosphoinositide 3-kinase/AKT pathway. Proc Natl Acad Sci USA 96: 4240-4245, 1999.

39. Balachandran VP, Cavnar MJ, Zeng S, Bamboat ZM, Ocuin LM, Obaid H, Sorenson EC, Popow R, Ariyan C, Rossi F, et al: Imatinib potentiates antitumor $\mathrm{T}$ cell responses in gastrointestinal stromal tu mor through the inhibition of Ido. Nat Med 17: 1094-1100, 2011 